\title{
A Factor Analysis of Job Satisfaction among Hong Kong Physical Education Teachers 香港體育教師的工作滿足感因素分析
}

\author{
Robert Siu Kuen NG \\ Physical Education Section, \\ The Hong Kong Polytechnic University, HONG KONG
}

吳兆權

香港理工大學學生事務處體育組

\begin{abstract}
The primary purpose of this investigation was to assess the job satisfaction level of Hong Kong PE teachers. Other purpose was to examine the relationships between selected demographic variables and the job satisfaction level of certain work-related variables. A questionnaire was developed and contained the 82 job satisfaction items, demographic data and one 6-point Likert scales of the overall job satisfaction. The questionnaire was mailed to 444 Hong Kong PE teachers, and a total of 208 (46. $9 \%$ ) responses were returned by $115(55.3 \%)$ males and 85 (40.9\%) from primary schools. The majority of the respondents were aged between 26 and 45 years (78.4\%). The major findings were (a) 88.5\% of Hong Kong PE teachers were satisfied with their job; (b) a significantly positive correlation between PE teachers' overall job satisfaction and the 82 job satisfaction items; (c) no significant difference in overall job satisfaction between male and female PE teachers; (d) the top ten job satisfaction items were mainly intrinsic in nature while the lowest ten job satisfaction items were extrinsic factors. The subscale of principal relations and support was perceived to contribute most to the job satisfaction of Hong Kong PE teachers.
\end{abstract}

Keywords: job satisfaction, physical education, teachers, physical educators

\section{摘 要}

本文目的是探索香港體育敉師的工作滿足感, 利用因素分析方法找出影響其滿足感的主要因素。444份問卷採用分層隨機抽樣 寄出, 在二千年三至五月期間收回可應用問卷共 208 份, 回應率達 $46.9 \%$ 。結果顯示接近九成敉師滿意現在的工作, 十大最高和最低 的工作滿足感項目分別來自㸚學上的內在和外在因素。因素分析結果顯示, 香港體育敉師覺得與校長的關係和得到他的支持最為重要。

\section{Introduction}

The study of job satisfaction has been of great interest to behavioural science researchers (Brayfield \& Rothe, 1951; Fraser, 1983; Gruneberg, 1979; Hoppock, 1935; Hoy \& Miskel, 1996; Kalleberg, 1977; Locke, 1976; Mumford, 1972; Poppleton, 1988; Portigal, 1976; Quarstein, McAfee \& Glassman, 1992; Smith, Kendall \& Hulin, 1969; Vroom, 1964). In sum, job satisfaction has been viewed from two theoretical frameworks:
(1) content theories which include the hierarchy of needs theory (Maslow, 1943) and two-factor theory (Ewen, Smith, Hulin \& Locke, 1966; Herzberg, 1966; 1968; Herzberg, Mausner \& Synderman, 1993; King, 1970); (2) process or discrepancy theories which consist of the expectancy theory of motivation (Vroom, 1964), equity theory (Adam, 1963), discrepancy theory (Locke, 1969), path-goal theory (Georgopoulos, Mahoney \& Jones, 1957), value fulfilment theory (Kuhlin, 1963) and reference group theory (Hulin \& Blood, 1968). 
This study was designed to assess the job satisfaction level of Hong Kong PE teachers. A second purpose was to identify the major factors of job satisfaction in teaching PE. A further aim was to examine the relationships between selected demographic variables and the job satisfaction level of certain work-related variables.

In Hong Kong teaching has long been plagued with problems of low morale and high resignation rates (Education Commission, 1992; Subsidized Secondary School Council, 1990). The findings of the Hong Kong Teacher Survey in 1995 (Hong Kong Education Department, 1996) showed that 9.2 per cent and 9.5 per cent of teachers from primary and secondary schools respectively dropped out from teaching in the 1994/95 academic year. The dropout rate for PE teachers was 2.4 per cent and 2. 9 per cent for primary and secondary school teachers respectively. The resultant drop-out rate showed a slight increase when compared to the previous year. This might suggest a related drop in job satisfaction in the PE career. $\mathrm{Ng}$ (1998) investigated 181 Hong Kong PE teachers and found that a relatively high proportion in his sample were dissatisfied or very dissatisfied with the subscales of 'work on present job' (35.4\%), 'present pay' (68.5\%), 'promotion’ (79.6\%), 'supervision' (40.9\%), 'coworkers' (35.9\%) and 'job in general' (36.1\%). This negative feeling might stimulate their intention to quit PE teaching or to leave a teaching career. $\mathrm{Ng}$ (1998) found that respondents indicated a high intention not to teach PE (17.7 per cent) and to leave teaching (26.0 per cent) within five years. A similar finding was reported by Chan, Lau and Hui (2001) where 13.1 per cent of respondents indicated the intention of quitting a PE career in the following five years. Although their intentions to leave PE and a teaching career may have been an extreme response, it was a way for them to express their feelings of dissatisfaction.

\section{Methodology}

\section{Population and Participants}

The population comprised all PE teachers in Hong Kong. There were a total of 1,135 schools, including 740 primary and 395 secondary schools from 19 districts in Hong Kong. Teachers in private international schools and special schools were excluded from the sample population. Research participants included full-time PE teachers of primary and secondary schools in Hong Kong.

\section{Sample}

As there were no existing name lists of all PE teachers in Hong Kong, schools were randomly selected as the primary sampling units and were stratified to: a) reflect equal numbers of teachers from primary and secondary schools; and b) represent a proportional percentage of teachers from three different districts, including aided and government schools. The sample for this study included 444 PE teachers from 444 schools which represented 246 primary schools and 198 secondary schools. A higher sampling fraction was employed for secondary schools to ensure adequate representation of cases in this stratum as a domain of study. If there was more than one PE teacher in a school, the principal was asked to distribute the questionnaire randomly to one of them.

\section{Data Collection}

Independent variable - The four page questionnaire consisted of two sections. The first section assessed the satisfaction level of respondents related to eighty-two satisfaction items. Measures were drawn from a number of previously developed instruments and adapted for this work. In each case, attempts were made to use measures that had been designed for use in school settings. Respondents were asked to indicate their satisfaction with each item on a seven-point Likert scale: $0=$ not relevant, 1=highly dissatisfied, 2=moderately dissatisfied, $3=$ =lightly dissatisfied, $4=$ =slightly satisfied, $5=$ moderately satisfied and $6=$ highly satisfied. The overall level of satisfaction with each independent variable was assessed. For all scales, a high mean scale score indicates high global job satisfaction. Biographical information was requested in the final section of the questionnaire, including personal and professional characteristics of the respondents. Based on previous questionnaires in the literature, this included marital status, chronological age, gender, years of teaching experience, subjects taught, preference for teaching or coaching, sports participation background, medium of instruction used, gender of their principals, school type, and location of school.

Dependent variable - Overall job satisfaction - The degree of overall job satisfaction as a PE teacher was directly measured by a 6 -point rating scale that ranged from 1 (highly dissatisfied) to 6 (highly satisfied).

\section{Procedures for Main Study}

In early March 2000, a complete questionnaire package which contained a covering letter, questionnaire, and stamped return envelope was mailed to selected 444 primary and secondary schools. The researcher asked principals from the selected 
schools to distribute the questionnaires randomly to one of their PE teachers with the covering letter explaining the purpose of the study and an indication that participation was voluntary. No names of participants were used, and the confidentiality of responses was maintained by participants mailing their responses in the self-addressed and stamped envelopes provided. It was believed that the method to distribute and collect the questionnaires would result in enhanced response rates. All selected participants were requested to send back the questionnaires to the investigator even if they were not willing to participate in the investigation. Each questionnaire was coded to facilitate follow-up activities.

In early April 2000, a follow-up letter together with another questionnaire was sent to non-respondents. A further questionnaire was sent to non-respondents in late April 2000. By 31 May 2000, a total of 236 questionnaires had been received, which consisted of 172 questionnaires received in the first response and 64 after the follow-up activity. This represented a 53.15 per cent response rate. However, 28 questionnaires were discarded because they were incomplete. The total usable sample was 208, 122 from secondary and 86 from primary schools, representing a 46.85 per cent response rate. There is similar proportion of the respondents and the sample from the three different geographic districts, that is, 4:6:10 from districts of Hong Kong, Kowloon and New Terrorities respectively. The sample size of 208 is representative of the whole population of Hong Kong PE teachers.

\section{Statistical Analysis}

Scale refinement - Some of the items adapted from previous studies might be unsuited to the Hong Kong situation or PE teachers. Therefore, a principal components factor analysis was conducted on the data from the 82 job satisfaction items to determine whether it was valid to reorganise them, and reduce the data.

Factor analysis was performed using SPSS-X Factor (Norusis, 1990). The initial factor extraction was followed by Varimax rotation to an oblique solution. The number of factors to be extracted was determined by both the scree test and eigenvalues greater than one. Bartlett's Test of Sphericity gave a test statistic level of $\mathrm{p}<.0001$ and the Kaiser-MeyerOlkin Measure of Sampling Adequacy (KMO) was 0.83. The criteria for selection of an item to represent a factor were (a) the item should load 0.45 or higher on the factor, and (b) its loading on the factor should be higher by at least 0.1 than its loadings on other factors (Kim \& Mueller, 1978). Using these criteria, twenty factors were extracted, explaining 76.1 per cent of the total variance. After factors with less than three items and less than three per cent of the total variance were excluded, the Varimax-rotated thirteen-factor solution which consisted of 72 items yielded the most interpretable solution. The thirteen factors accounted for 62.8 per cent of the total variance. The loading of each item on its dominant component is presented in Table 1. The principal support and relations subscale accounted for 10.3 per cent of variance. The explanation power achieved in the present study was good when compared with other teacher job satisfaction studies of Haughey and Murphy (1983), Pelsma and colleagues (1989), and McCormick (1997) which accounted for 47 per cent, 66. 3 per cent and 54 per cent of the total variance respectively.

Scoring - The satisfaction score for each of the thirteen factors was obtained by taking the mean score across the items making up that factor.

Table 1. Varimax-related Thirteen-factor Solution of Sources of Job Satisfaction $(N=184)$.

\begin{tabular}{lc}
\hline \multicolumn{1}{c}{ Job satisfaction item } & Loading \\
\hline Factor 1 & .838 \\
Your overall level of satisfaction with the relations with your principal. & .788 \\
Educational leadership of the principal. & .771 \\
The extent to which the principal has trust and confidence in the teachers. & .758 \\
Clarity of principal's expectations. & .740 \\
Principal keeps you informed about matters related to your job. & .714 \\
The amount of personal support given to teachers by the principal. & .660 \\
Availability of useful advice to assist you with problems you encounter in teaching or coaching. & .640 \\
Clarity of school goal. & .636 \\
Your relationship with the principal. & .618 \\
Your overall level of satisfaction with the support from senior management. & .581 \\
Central office administrators are supportive of individual teachers. & .568 \\
Fairness in treatment of all teachers.
\end{tabular}


Table 1 (continued)

Job satisfaction item

Loading

Factor 2

Professional Autonomy

$(7.0 \%$ of variance)

Your freedom to determine methods of assessing students.

Your freedom to select subject matters for your classes.

To handle problems associated with teaching.

Your freedom to select teaching methods.

To handle problems associated with training.

The degree of involvement in the decision making process.

Your overall level of satisfaction with professional autonomy.

To handle problems associated with competition.

Factor 3

Resource Availability

(6.4\% of variance)

Your overall level of satisfaction with resource availability.

The distribution of resources within your school.

The physical conditions of the teaching aids and equipment.

The distribution of resources to your school.

The physical conditions of the teaching place such as classrooms, laboratory and venue.

The availability of materials/equipment for your teaching.

$(6.3 \%$ of variance $)$

Your overall level of satisfaction with students' attitude.

The level of student achievement in your classes.

The attitudes of students towards learning.

The conduct and discipline of students in your classes.

The school climate of learning.

The ability level of students in your classes.

The amount of time you work after school hours on weekdays.

The amount of time you work during weekends and holidays.

The amount of time spent on non-teaching duties each week such as administrative work,

extra-curricular activities, coaching and competitions.

Your overall level of satisfaction with your workload.

The amount of time available for your family and/or friends.

The number of non-teaching periods during the school week.

The size of the classes you teach e.g. number of students.

The distribution of workload within your school.

( $4.8 \%$ of variance)

Status of teachers in society.

Attitude of society towards teachers.

Your overall level of satisfaction with professional recognition.

Recognition of teacher achievement by the supervisor.

Recognition by other teachers in the school of your work.

Teacher input into school board.

Your sense of achievement in teaching. 
Table 1 (continued)

\begin{tabular}{lc}
\hline Job satisfaction item & Loading \\
\hline
\end{tabular}

Factor 8

Working Conditions

(3.9\% of variance)

The prospect of classroom teaching as your lifetime career. $\quad .755$

The condition of teachers room.

Yoür overall level of satisfaction with your working conditions.

Teaching environment and climate in your school.

Your job security.

Factor 9 Support for Special Needs Students (3.1\% of variance)

Support services available for integrated special needs students.

Policy of integration of special needs students into the regular classroom.

Factor $10 \quad$ Staff Development

(3.1\% of variance)

The extent to which staff are granted leave for further studies.

Your overall level of satisfaction with staff development in your school.

Opportunities for useful in-service education.

$\begin{array}{lr}\text { Factor } 11 & \text { Extrinsic Rewards (3.0\% of variance) } \\ \text { Your overall level of satisfaction with your promotion opportunity. } & .702 \\ \text { The factors used to determine salaries. } & .677 \\ \text { Methods used to evaluate teachers for promotion. } & .654 \\ \text { Your overall level of satisfaction with your salary. } & .619\end{array}$

Factor 12 Parental Support (2.9\% of variance)

Your overall level of satisfaction with the parents of your students. 777

The amount of involvement of parents in school activities. $\quad .718$

$\begin{array}{ll}\text { The parents of your students are supportive. } & .651\end{array}$

Factor $13 \quad$ Students' Progress (2.3\% of variance)

The achieved results of inter-school competitions.

Your overall level of satisfaction with students' progress.

The attitudes of students toward participating school sports teams. .491

All data were analyzed using SPSS version 7.0. In phase one, the internal consistency reliability estimate for each subscale was assessed using Cronbach's coefficient alpha. In phase two, the 72 items on the questionnaire were inter-correlated with overall job satisfaction using Pearson product moment correlation coefficients. The 0.05 level was employed to evaluate the significance of the statistical relationships. Finally, the relationships of biographic information to job satisfaction subscales were examined by means of a series of t-test and one way analysis of variance (ANOVA).

\section{Resullts and Discussions}

\section{Personal and Professional Characteristics of Respondents}

The respondents in this study were 208 Hong Kong PE teachers, 85 from primary schools and 123 from secondary schools. There were slightly more males (55.3 per cent) than females (44.7 per cent) and the majority of the respondents were aged between 26 and 45 years (78.4 per cent). Most of the respondents were married (60.6 per cent) and had two or more dependents residing at home (74.7 per cent). Half of the respondents ( 50.0 per cent) worked in the New Territories district. The vast majority of the respondents (85.6 per cent) used Chinese as a medium of instruction. Concerning the number of pupils in school, 46.2 per cent and 41.8 per cent of the respondents taught in schools with 500-1,000 pupils and 1,001-1,500 pupils respectively.

One fifth (20.7 per cent) of the respondents had less than six years teaching experience while about half of the respondents (49.0 per cent) had between six and fifteen years of teaching experience. More than one third (38.0 per cent) of the respondents had spent less than six years of service in their current school. The respondents were predominantly 
university graduates (51.4 per cent) and more than one third (35.1 per cent) had a teacher's certificate. The vast majority of the respondents (98.6 per cent) were on a permanent fulltime contract. With regard to the job title of the respondents, the most common categories were certificated master/mistress (39.9 per cent) and graduated master/mistress (21.2 per cent). Sixty-two per cent of respondents reported that the principal was male.

The major subject taught of the respondents were cultural subjects (38.9 per cent) and academic subjects (32.2 per cent), while 28.8 per cent of the respondents taught nearly equal proportions of the subjects. The vast majority of the respondents (90.9 per cent) generally reported that their assignments were consistent with their training.

Regarding the preference for teaching or coaching, about two fifth (38.5 per cent) preferred teaching, one fifth (18.3 per cent) preferred coaching and most of the respondents (43.3 per cent) reported no special preference. The majority of the respondents (61.1 per cent) were former or present athletes, representing their school (47.6 per cent), district (6.3 per cent), or Hong Kong (7.2 per cent). The majority of the respondents rated their performance as a PE teacher to be good (69.7 per cent).

\section{Overall Satisfaction Level}

In the present study, 88.5 per cent of the Hong Kong PE teachers reported that they were satisfied with their work as PE teachers. Compared with other studies of Hong Kong teachers, this finding is similar to Tse's (1982) study, in which 93 per cent of Hong Kong secondary school teachers reported themselves to be satisfied or very satisfied with their job. Additional support comes from the finding of a survey on Hong Kong teachers' job satisfaction in 2001 by the Education Department (2001), in which 70.1 per cent and 70.9 per cent of teachers from primary and secondary schools were satisfied or very satisfied with the nature of their job. However, Hui and Chan (1996) found that only 57 per cent of Hong Kong teachers were satisfied with their present job. It also contrasts with the study by $\mathrm{Ng}$ (1998) who assessed the job satisfaction of Hong Kong PE teachers using the Job descriptive Index (JDI) and the Job in General (JIG) instrument, finding that only 46.1 per cent of Hong Kong PE teachers were satisfied or very satisfied with their jobs.

There are two factors that may explain the great difference in the measured job satisfaction levels. First, it may have been due to the different instruments applied in the two studies, using either single item in the present study or facet measures in the study of $\mathrm{Ng}$ (1998). Moreover, it may reflect changes over different period of time. The study of $\mathrm{Ng}$ (1998) and the present study collected data from Hong Kong PE teachers in 1996 and 2000 respectively. There were political and economic changes between these two period of time. Hong Kong became a Special Administration Region (SAR) of the People's Republic of China on July 1, 1997, after a century and a half of British administration. The employment situation in Hong Kong deteriorated severely after the outbreak of the Asian financial crisis in 1998. According to the Census and Statistics Department (2002), the unemployment rate increased from 2.6 per cent in 1996 to 4.4 per cent in 2000, with an upward trend continuing to 7.9 per cent in 2002. In addition, property prices were 40 to 50 per cent lower than the peak after the Asian financial crisis; a further drop would be considered by many as destructive to the economy. Competition for employment was keen, especially a job with high security like teaching. Like commercial companies in Hong Kong, the Hong Kong SAR Government carried out some 'slimming' down such as cutting civil servants' starting salaries by 6 . 0 to 31.0 per cent in 1999 and new employed teachers were affected under this plan. However, there were no changes for existing teachers in terms of salary. Therefore, PE teachers in the present study may have felt more satisfied than those in Ng's (1998) earlier study since teaching was regarded as a stable career in this critical period with a high salary.

\section{The Top Ten and the Lowest Ten Job Satisfaction Items}

The top ten job satisfaction items in Table 2 are mainly intrinsic in nature such as professional autonomy and relationships with students. This underscores the association between teacher job satisfaction and autonomy at work (Hall, Pearson \& Carroll, 1992; Kreis \& Brockoff, 1986). It also supports the observations of Chelladurai and Kuga (1996) who found perceived autonomy came from the coaching role of PE teachers which provides control over the selection and retention of team members, and their degree of participation in competition. The results reinforce the work of Brunetti (2001), Dinham and Scott (1998, 2000), Friesen, Holdaway and Rice (1983), Haughey and Murphy (1983), Herzberg (1968), Holdaway (1978), Lester (1985), Lortie (1975), and Miskel (1982) who argue that teachers are most satisfied by intrinsic aspects of their job. These include interactions with students, psychic rewards, psychological growth, and professional autonomy. These findings imply that teachers place great value on the professional subscales of their occupation. This is also in line with the findings of Pastor and Erlandson (1982), who applied the concept of Maslow's (1970) higher 
and lower order needs to secondary public school teachers. They found that higher order needs such as autonomy, variety, and the use of valued skills are the main areas of job satisfaction. In contrast, some investigators have a different viewpoint regarding autonomy (Chelladurai \& Kuga, 1996). Within their classrooms and playgrounds many PE teachers are not able to design their own work, having to meet well-defined objectives and cover all the contents of the curriculum. What initially appears as autonomy is felt by many as isolation.

\section{The Lowest Ten Job Satisfaction Items}

The lowest ten items displayed in Table 3 are more diffuse and extrinsic. They are related to workload, parental involvement, promotion method, salary determination, and the availability of support services for integrating special needs students. This supports the findings of a survey of Hong Kong teachers' job satisfaction in 2001 (Education Department, 2001) that only 44.4 per cent and 28.0 per cent of teachers from primary and secondary schools respectively were satisfied or very satisfied with support from parents. Consistent with the findings of Dinham and Scott (1998, 2000), Lester (1985), and Pastor and Erlandson (1982), the reported areas of job dissatisfaction come from Maslow's (1970) lower order needs corresponding to extrinsic work factors, such as working conditions, supervision, work policy, salary, and interpersonal relationships. Some factors may be inter-correlated, like the heavy workload which may come from an inadequate support service and result in limited time for families and/or friends.

Table 2. The Top Ten Items of Job Satisfaction.

\begin{tabular}{llcl}
\hline Rank & \multicolumn{1}{c}{ The top ten job satisfaction items } & Mean & S.D. \\
\hline 1 & Your freedom to select teaching methods. $(N=208)$ & 4.89 & 0.86 \\
2 & Your relationship with students. $(N=208)$ & 4.84 & 0.74 \\
3 & Your freedom to determine methods of assessing students. $(N=207)$ & 4.65 & 1.03 \\
4 & To handle problems associated with teaching. $(N=208)$ & 4.59 & 0.84 \\
5 & To handle problems associated with training. $(N=206)$ & 4.51 & 0.99 \\
6 & The total number of school holidays (e.g. Christmas and Lunar New Year). $(N=207)$ & 4.48 & 1.03 \\
7 & The degree of involvement in the decision making process. $(N=206)$ & 4.43 & 0.99 \\
8 & To handle problems associated with competition. $(N=205)$ & 4.42 & 1.06 \\
9 & Your overall level of satisfaction with professional autonomy. $(N=207)$ & 4.41 & 0.84 \\
10 & Your freedom to select subject matter for your classes. $(N=206)$ & 4.37 & 1.26 \\
\hline
\end{tabular}

Note: $N=$ number of respondents, excluding incomplete responses; S.D. = standard deviation

Table 3. The Lowest Ten Items of Job Satisfaction.

\begin{tabular}{|c|c|c|c|}
\hline Rank & The lowest ten job satisfaction items & Mean & S.D. \\
\hline 1 & $\begin{array}{l}\text { The amount of time spent on non-teaching duties each week such as administrative } \\
\text { work, extra-curricular activities, coaching and competitions. }(N=208)\end{array}$ & 2.73 & 1.27 \\
\hline 2 & The amount of involvement of parents in school activities. $(N=208)$ & 2.89 & 1.38 \\
\hline 3 & The amount of time you work after school hours on weekdays. $(N=191)$ & 2.97 & 1.23 \\
\hline 4 & The number of non-teaching periods during the school week. $(N=193)$ & 3.04 & 1.44 \\
\hline 5 & Methods used to evaluate teachers for promotion. $(N=208)$ & 3.08 & 1.38 \\
\hline 6. & The amount of time you work during weekends and holidays. $(N=208)$ & 3.11 & 1.22 \\
\hline 7 & The amount of time available for your family and/or friends. $(N=208)$ & 3.13 & 1.26 \\
\hline 8 & The amount of time spent in meetings. $(N=202)$ & 3.21 & 1.26 \\
\hline 9 & The factors used to determine salaries. $(N=185)$ & 3.25 & 1.54 \\
\hline 10 & Support services available for integrated special needs students. $(N=194)$ & 3.26 & 1.31 \\
\hline
\end{tabular}

Note: $N=$ number of respondents, excluding incomplete responses; S.D. = standard deviation 


\section{Reliability of the Scales}

In an attempt to understand the relationship between the thirteen job satisfaction subscales, an internal consistency reliability estimate for each subscale was carried out, followed by a Pearson product moment correlation among the facets in the subscales. The internal consistency reliability estimate, using Cronbach's coefficient alpha, ranged from $\alpha=.753$ (students' progress subscale) to $\alpha=.948$ (principal support and relations subscale) for the thirteen job satisfaction subscales (see Table 4).

Table 4. Number of Items and Internal Consistency Reliabilities of the Overall Level of Job Satisfaction Subscales $(\mathrm{N}=184)$.

\begin{tabular}{lcc}
\hline Subscales of the overall level of job satisfaction & Number of items & Internal Consistency Reliability \\
\hline Principal Support and Relations & 12 & .948 \\
Support for Special Needs Students & 2 & .936 \\
Resource Availability & 6 & .932 \\
Professional Autonomy & 8 & .914 \\
Parental Support & 3 & .899 \\
Students' Attitudes & 6 & .888 \\
Staff Development & 3 & .883 \\
Professional Recognition & 7 & .868 \\
Workload & 8 & .866 \\
Working Conditions & 5 & .866 \\
Collegiality & 5 & .827 \\
Extrinsic Rewards & 4 & .765 \\
Students' Progress & 3 & .753 \\
\hline
\end{tabular}

Total : 72

\section{Association with Overall Satisfaction}

Pearson product-moment correlations were computed for all variables to provide an initial look at relationships among the dependent variables in the questionnaire. Correlation matrixes revealed low to moderate correlations between overall satisfaction with work as a PE teacher and each of the 72 questionnaire items. All correlation coefficients were positively related, ranging from $r=.175$ to $r=.603$ and significant at the 0.01 or 0.05 levels. Item with the highest correlation coefficient was 'your overall level of satisfaction with your working conditions' $(r=.603)$. Items with the lowest correlation coefficient were 'the number of non-teaching periods during the school week' $(r=.175)$, and 'the achieved results of inter-school competitions' $(r=.175)$. This supports the study by Holdaway (1978) showing high correlation between singleitem measures of satisfaction and facet satisfaction.

When the results of the lowest ten Pearson correlation coefficients are compared with the lowest ten items of job satisfaction (see Table 3), it is interesting to notice that four out of ten items were the same. They were the number of non-teaching periods during the school week', 'the amount of time you work during weekends and holidays', 'the amount of time available for your friends and/or family' and 'the factors used to determine salaries'. Three items were concerned with workload and the other with extrinsic benefit.

According to Bogler (2001) and Sergiovanni (1967), there are intrinsic and extrinsic aspects of a teacher's occupation. Intrinsic dimensions relate to aspects of teaching such as work autonomy, status, staff development, and self-esteem. Extrinsic properties refer to the physical aspects of the working place and to its financial rewards. It is worth noting that eight out of the ten strongest predictors of overall satisfaction in the present study were extrinsic in nature. Five extrinsic factors were related to the principal and senior management, their relations, their support, their leadership, and being informed about matters related to the job. This is in agreement with the findings of Bogler (2001) and Chapman and Lowther (1982) in that the recognition and support received from administrators 
and supervisors had a strong positive impact on teacher job satisfaction. This finding is in line with the results of factor analysis where the principal support and relations subscale is the main predictor of job satisfaction of Hong Kong PE teachers. The other extrinsic aspects were working conditions, teaching climate and workload. The intrinsic factors included professional recognition and sense of achievement.

\section{Comparison between Demographic Characteristics, the Work Environment, and Job Satisfaction}

A series of t-tests and ANOVA tests were performed, using the mean score for the thirteen subscales and mean score for the overall level of job satisfaction as dependent variables, to examine the perceived job satisfaction of teachers with reference to their demographic characteristics and the work environment.

\section{Comparison between Gender Difference}

Male PE teachers felt more satisfied than female PE teachers in the subscales of principal support and relations, professional autonomy and resource availability. The finding confirms the importance of teacher autonomy identified by Knoppers (1987) that also revealed male coaches had more autonomy than their female counterparts. However, there is no significant difference regarding gender in the overall satisfaction level of work as a PE teacher. When comparing teachers performing teaching and coaching roles, similar findings were identified by Ng (1998) and Chan, Lau and Hui (2001) in which no significant difference between job satisfaction levels for Hong Kong male and female PE teachers was found.

\section{Marital Status}

There was no significant difference between single and married teachers in the thirteen job satisfaction subscales. This finding is consistent with the earlier work by $\mathrm{Ng}$ (1998) who surveyed 181 Hong Kong PE teachers. He found no significant difference in overall satisfaction level between single and married teachers.

\section{Comparison between School Type}

In spite of Hong Kong primary and secondary schools are relatively homogeneous in terms of promotion structure, salary structure, professional qualifications, teacher-class ratios, school facilities, curricula, supporting personnel (such as technical, clerical, cleaning staff), staff development, and supervision by the Hong Kong Department of Education (Education Commission, 1996). It is noteworthy that PE teachers who taught in primary schools were significantly more satisfied than secondary school teachers with respect to principal support and relations ( $\mathrm{t}=3.942, \mathrm{df}=206, p=.000$ ), students' attitudes $(\mathrm{t}=4.340, \mathrm{df}=206, p=.000)$, workload $(\mathrm{t}=3.818$, df $=206, p=.000)$, professional recognition $(\mathrm{t}=2.787$, $\mathrm{df}=$ 206, $p=.006)$, collegiality $(\mathrm{t}=3.231, \mathrm{df}=206, p=.001)$, support for special needs students $(\mathrm{t}=2.649$, df $=206, p$ $=.009)$, staff development $(\mathrm{t}=2.628, \mathrm{df}=206, p=.009)$, extrinsic rewards $(t=3.539, \mathrm{df}=206, p=.000)$, parental support $(\mathrm{t}=5.338, \mathrm{df}=206, p=.000)$, and students' progress $(\mathrm{t}=2.330, \mathrm{df}=206, p=.021)$. The exception was professional autonomy $(\mathrm{t}=-3.928$, $\mathrm{df}=206, p=.000)$ where PE teachers who taught in secondary schools expressed greater satisfaction.

There is no standard in how many sport teams a PE teacher has to coach, since it depends on the resources available and is up to the Panel Head and the Principal to decide. The majority of primary schools in Hong Kong operate in half-days and the facilities like classroom and playground are shared between two schools in the morning and afternoon. Since there is no venue for teachers in primary schools to train school teams after school, the workload regarding the time spent on school team training and organizing competitions like sports day and swimming galas in most primary schools is less than that in secondary schools. In the current study, the higher perception of job satisfaction of primary school teachers in these subscales may be as a result of the positive attitude of the students towards sports, the lower demands of school teams, and the shorter working hours in primary schools. The overall satisfaction level of a PE teacher is not significantly affected by school type. This result is consistent with the findings of Perkins (1991) and $\mathrm{Ng}$ (1998) that no significant difference in overall satisfaction level was found between teachers in primary and secondary schools.

\section{Preference of Teaching and Coaching}

The current study showed that about half of the respondents expressed an equal commitment to teaching and coaching, about two thirds of males and half of females expressed greater preference for coaching and teaching respectively. This is in contrast with the findings of other investigations (Bain \& Wendt, 1983; Segrave, 1981) where many pre-service PE teachers reduce role conflict by having a preference for one role over the other. The fact that only about one-fifth of Hong Kong PE teachers prefer coaching may be due to the additional pressure since coaching, (sometimes of more than one sport), is additional to a teacher's normal workload. According to the Hong Kong Education Department (Education Commission, 1998), time spent coaching school teams has also increased and become a large part of a Hong Kong 
PE teacher's workload. Compared with 1988/89, there was a 9.6 per cent and 17.5 per cent increase in the number of students from primary and secondary schools participating in inter-school and inter-port sports events organized by the Hong Kong Schools Sports Federation during 2000/01. There were 16.9 per cent and 25.1 per cent of pupils in primary and secondary schools participating in inter-school and interport sports events in the academic year of $2000 / 01$.

\section{Comparison between Sports Participation Background}

It has been found that a love of sports and physical activity is an influential factor in choosing a physical education profession (Stroot et al., 1994; Templin et al., 1994). Results of the univariate analysis, indicating that teachers with a good sports participation background, such as a former or present athlete, expressed more satisfaction with professional autonomy $(\mathrm{t}=2.807, \mathrm{df}=206, P=.005)$ than their non-sporting counterparts. The results were consistent with the findings of Segrave (1981) that pre-service PE teachers who were athletes expressed greater interest in coaching than non-athletes.

\section{Comparison between Consistency of Assignment with Training}

Teachers with consistency of assignment with training, expressed more satisfaction with working conditions $(t=2$. 318, d.f. $=206, P=.016)$ and work as a PE teacher $(\mathrm{t}=$ 2.507 , d.f. $=206, P=.013)$ than their counterpart. This may be due to the existing educational situation in Hong Kong where PE teachers are required to coach school teams in which they have not been trained in the teacher training course. Proctor, Rowlands, and Thornton (1989) described this as "professional mugging" and a source of tension and job dissatisfaction. $\mathrm{Ng}$ (2002) stated that there is no formal coursework like skills and attitudes in Hong Kong PE teachers preparation to train students for the coaching role. Although some teachers might see this as a source of challenge and job satisfaction it might equally be the case that this mismatch between training and responsibility is a source of tension and could well be a reason for job dissatisfaction.

\section{Comparison between Gender of Principal}

Results indicated that the respondents with a female principal derived more satisfaction from the parental support of the student ( $t=-2.075$, df $=206, p=.039)$, than did respondents with a male principal. This observation is consistent with the findings of Heller, Clay and Perkins (1993) that teacher satisfaction was not significantly affected by background variables such as principal gender.

\section{Comparison between Medium of Instruction}

Data from the primary PE teachers were excluded as only secondary schools use either English or Chinese as the medium of instruction. The difference in medium of instruction may influence communication and relations between students and teachers that, in turn, affect their level of job satisfaction. The results indicated that respondents using English as the medium of instruction were more satisfied with respect to students' attitude ( $\mathrm{t}=3.634, \mathrm{df}=121, p=.000)$, and parental support of the student $(t=3.260$, df $=121, p=.001)$.

PE teachers in schools using English as a medium of instruction expressed more satisfaction than those using Chinese regarding students' attitudes, parental support, and principal support and relations. This relates to the recent transition from the use of Chinese to English as the medium of instruction on educational grounds in 114 secondary schools. Many parents have expressed serious concern about the language proficiency of their children as they still think that using English as the medium of instruction is the only way to master the English language (Law, 1999). They complained to school principals when English is not the medium of instruction for their children.

\section{Comparison among Three Districts (Hong Kong Islands, Kowloon, and New Territories)}

One-way ANOVA was applied to investigate whether teaching in different geographic districts in Hong Kong affected perceived job satisfaction. There were 43, 61 and 104 respondents who taught in Hong Kong, Kowloon, and the New Terrorities respectively. The $F$-ratio indicated that all variables were non-significant apart from the dependent variable of 'overall satisfaction with resource availability' $(F[2,205]=3.522, p$ $=.031$ ). A Scheffe's post hoc procedure was utilized to identify the source of differences. Regarding satisfaction level with resource availability, results in the Scheffe's post hoc testing showed that there was no significant difference among the PE teachers from the three districts.

The International Congress for School Effectiveness (Law, 1999) reported that the majority of the newly established schools in Hong Kong are located in the New Territories which provide more space for PE. Therefore, it is not surprising that the PE teachers in the New Territories were more satisfied with resource availability than their counterparts in the Kowloon district. 


\section{Comparison among the Subject Taught (Academic, Cultural, More or Less the Same)}

The aim was to determine whether teachers with different proportions of the subject taught differed in their job satisfaction. There were 81, 67 and 60 respondents who taught the majority of cultural subjects, academic subjects, and more or less the same respectively. The $F$ ratio obtained from ANOVA indicated that all variables were non-significant apart from the dependent variable of 'overall satisfaction with professional autonomy' $(F[2,205]=7.412, p=.001)$, and 'overall satisfaction with parental support' $(F[2,205]=3.291, p=.039)$. Results in the Scheffe's post hoc testing showed that respondents who taught cultural subjects like PE most of the time expressed more satisfaction with professional autonomy than those who taught academic subjects for the majority of the time. Regarding the satisfaction level with the parental support, results in the Scheffe's post hoc testing showed that no significant effect, or interaction effects were noted.

This is because PE teachers have autonomy to decide the content and method in the internal PE examination especially if the teachers taught all the PE lessons. The present result reinforces the work by Chelladurai and Kuga (1996) concerning PE teachers who have autonomy to carry out their coaching and teaching tasks.

\section{Age / Teaching Experiences / Teaching Position}

Age, teaching experience and teaching position of the $\mathrm{PE}$ teachers in the present study were analysed in relation to the thirteen job satisfaction subscales. Teachers who were 46 years-old or over were more satisfied than their younger counterparts in the subscales of promotion and work as a PE teacher. Regarding the overall satisfaction with work as a PE teacher, teachers with more than 21 years teaching experience were more satisfied than teachers with 6 - 10 years teaching experience. Similar findings were identified by Billingsley and Cross (1992), Kacmar and Ferris (1989), Lee and Wilbur (1985), and Parasuraman (1982) that job satisfaction increases linearly with age. One explanation is that teachers with longer experience who are probably older and have been in the job longer, may have attained more of what they want than their younger counterparts and those who have not may either have left, or have lowered their aspirations to reflect what they are able to get.

Conversely, Reese and Johnson (1991) reported that the years of teaching experience was not found to be a significant factor in the job satisfaction level of high school PE teachers. Similarly teachers with senior positions expressed more satisfaction with promotion opportunities and professional autonomy than their junior counterparts. This reflects the likely achievement of autonomy as a result of promotion. However, there is no significant difference in the overall level of job satisfaction as a PE teacher between junior and senior teachers as found by $\mathrm{Ng}$ (1998). At the same time, younger teachers in the present study felt more satisfied than the older teachers as regards workload. This may be due to the heavy workload incurred by promotion to panel chairperson or the high physical and mental demands perceived at an older age.

\section{Conclusion}

The majority (88.5\%) of the Hong Kong PE teachers in the present study reported that they were satisfied with their work as PE teachers. Results showed that there is high correlation between single-item measures of satisfaction and facet satisfaction. The results in the top ten job satisfaction items reported that the sources of job satisfaction came from intrinsic aspects of their job which correspond to Maslow's (1970) higher order needs. Conversely, the lowest ten job satisfaction items were extrinsic in nature which come from Maslow's (1970) lower order needs. The principal support and relations subscale accounts for the major construct of job satisfaction of Hong Kong PE teachers. Considerable research is needed to assess directly whether the causal relationships proposed in the framework are operative in job satisfaction. Finally, the ideas proposed in this model also suggest a new view regarding the job satisfaction of Hong Kong PE teachers - perhaps a starting point - from which to interpret the job satisfaction of Hong Kong PE teachers.

Future research should also be continued to investigate the influence on job satisfaction level if coaching duties involve PE teachers coaching more than one sport or team. The methodology can be developed using qualitative methods such as interviews and case studies of teachers in order to explore the meaning behind the findings. For example what kind of teaching or coaching roles that the PE teachers like or dislike? Finally, it might be illuminating to examine the influence of teacher stress and cultural factors on job satisfaction of Hong Kong PE teachers. 


\section{References}

Adams, J. S. (1963). Toward an understanding of inequity. Journal of Abnormal and Social Psychology, 67(5), 422436.

Bain, L. L., \& Wendt, J. C. (1983). Undergraduate physical education majors' perceptions of the roles of teacher and coach. Research Quarterly for Exercise and Sport, 54 (2), 112-118

Billingsley, B. S., \& Cross, L. H. (1992). Predictors of commitment, job satisfaction, and intent to stay in teaching: A comparison of general and special educators. The Journal of Special Education 25(4), 453-471.

Bogler, R. (2001). The influence of leadership style on teacher job satisfaction. Educational Administration Quarterly, 37(5), 662-683.

Brayfield, A. H., \& Rothe, H. F. (1951). An index of job satisfaction. Journal of Applied Psychology, 35, 805-814.

Brunetti, G. J. (2001). Why do they teach? A study of job satisfaction among long-term high school teachers. Teacher Education Quarterly, 28(3), 49-74.

Census and Statistics Department (2002). Retrieved 6 th July, 2002 from the World Wide Web: http:www.info.gov.hk/ censtatd/eng/hkstat/fas/labour/ghs/labour1.txt

Chan, R. C. M., Lau, Y. H., \& Hui, S. C. (2001). An evaluation of job satisfaction of physical education teachers in Hong Kong. International Sports Journal, 5(1), 60-70.

Chapman, D. W., \& Lowther, M. A. (1982). Teachers' satisfaction with teaching. Journal of Educational Research, 75(4), 241-247.

Chelladurai, P., \& Kuga, D. J. (1996). Teaching and coaching: Group and task differences. Quest, 48, 470-485.

Dinham, S., \& Scott, C. (1998). A three domain model of teacher and school executive career satisfaction. Journal of Educational Administration, 36(4), 362-378.

Dinham, S., \& Scott, C. (2000). Moving into the third, outer domain of teacher satisfaction. Journal of Educational Administration, 38(4), 379-396.
Education Commission (1992). Report No. 5. Hong Kong: Government Printer.

Education Commission (1996). Report No. 7: Quality school education. Hong Kong: Government Printer.

Education Commission (1998). Report No. 8. Hong Kong: Government Printer.

Education Department (2001). Abridged Report - Education Indicators for the Hong Kong School Education System. Education Department, Hong Kong: Author.

Ewen, R. B., Smith, P. C., Hulin, C. L., \& Locke, E. A. (1966). An empirical test of the Herzberg Two-factor Theory. In M. M. Gruneberg (1976). (ed.), Job Satisfaction - A Reader (pp.56-66). London: Macmillan Press Ltd.

Fraser, T. M. (1983). Occupation Safety and Health Series No. 50 - Human Stress, Work and Job Satisfaction: A Critical Approach. Geneva: International Labour Office.

Friesen, D., Holdaway, E. A., \& Rice, A. W. (1983). Satisfaction of school principal and their work. Educational Administration Quarterly, 19(4), 35-58.

Georgopoulos, B. S., Mahoney, G. M., \& Jones, J. N. W. (1957). A path-goal approach to productivity. Journal of Applied Psychology, 41(6), 345-353.

Gruneberg, M. M. (1979). Understanding Job Satisfaction. New York: Halston Press.

Hall, B. W., Pearson L., and Carroll, D. (1992). Teachers' long-range teaching plan: A discriminant analysis. Journal of Educational Research, 85(4), 221-225.

Haughey, M. L., \& Murphy, P. J. (1983). Are rural teachers satisfied with the quality of their work life? Education, 104(1), 56-66.

Heller, N., Clay, R., \& Perkins, C. (1993). The relationship between teacher job satisfaction and principal leadership style. Journal of School Leadership, 3, 74-82.

Herzberg, F. (1966). Work and the Nature of Man. New York: World Publishing Company. 
Herzberg, F. (1968). One more time: How do you motivate employees? In M. M. Gruneberg (1976). Job Satisfaction - A Reader (1 $1^{\text {st }}$ ed., pp.17-32). London: Macmillan Press Ltd.

Herzberg, F., Mausner, B., \& Snyderman, B. B. (1993). The Motivation to Work: With a New Introduction by Frederick Herzberg. New Brunswick: Transaction.

Holdaway, E. A. (1978). Facet and overall satisfaction of teachers. Educational Administration Quarterly, 14, 30-47.

Hong Kong Education Department (1996). Teacher Survey 1995. Statistics Section, Hong Kong: Author.

Hoppock, R. (1935). Job Satisfaction. New York: Harper and Row.

Hoy, W. K., \& Miskel. C. G. (1996). Educational Administration: Theory, Research and Practice (5 $5^{\text {th }}$ ed.). New York: McGraw-Hill.

Hui, E. K. P., \& Chan, D. W. (1996). Teacher stress and guidance work in Hong Kong secondary school teachers. Journal of Guidance and Counselling, 24(2) June, 199211.

Hulin, C. L. \& Blood, M. R. (1968). Job enlargement, individual differences, and worker responses. Psychology Bulletin, $69,41-65$.

Kacmar, K. M., \& Ferris, G. R. (1989). Theoretical and methodological considerations in the age-job satisfaction relationship. Journal of Applied Psychology, 74, 201207.

Kalleberg, A. L. (1977). Work values and job rewards: A theory of job satisfaction. American Sociological Review, 42(Feb.), 124-143.

Kim, J. O., \& Mueller, C. W. (1978). Factor Analysis: Statistical Methods and Practical Issues. Newbury Park, CA: Sage.

King, N. (1970). Clarification and evaluation of the two-factor theory of job satisfaction. In M. M. Gruneberg (1976). Job Satisfaction - A Reader (1 ${ }^{\text {st }}$ ed., pp. 33-55). London: Macmillan Press Ltd.
Knoppers, A. (1987). Gender and the coaching profession. Quest, 39, 9-22.

Kreis, K., \& Brockoff, D. Y. (1986). Autonomy: A component of teacher job satisfaction. Education, 107(1), 110-115.

Kuhlin, R. G. (1963). Needs, perceived needs satisfaction and satisfaction with occupation. Journal of Applied Psychology, 47, 57-64.

Law, F. C. F. (1999). International Congress for School Effectiveness and Improvement Plenary Session on January 5, 1999 at 4pm - In Pursuit of Excellence: Challenges and Changes for the Hong Kong Special Administrative Region. Hong Kong Special Administrative Region: Department of Education.

Lee, R., \& Wilbur, E. R. (1985). Age, education, job tenure, salary, job characteristics, and job satisfaction: A multivariate analysis. Human Relations, 38, 781-791.

Lester, P. E. (1985). Teacher job satisfaction K-12. Illinois School Research and Development, 22(1), Fall, 32-33.

Locke, E. A. (1969). What is job satisfaction? Organizational Behavior and Human Performance, 4(4), 309-336.

Locke, E. A. (1976). The nature and causes of job satisfaction. In M.D. Dunnette (ed.), Handbook of Industrial and Organizational Psychology (pp.1297-1349). New York: Wiley.

Lortie, D. C. (1975). Schoolteacher - A Sociological Study. Chicago: University of Chicago Press.

Maslow, A. H. (1943). A history of human motivation. Psychological Review, 50, 370-396.

Maslow, A. H. (1970). Motivation and Personality. New York: Harper and Row.

McCormick, J. (1997). An attribution model of teachers' occupational stress and job satisfaction in a large educational system. Work and Stress, 11(1), January, 17-32.

Miskel, C. (1982). Motivation in educational organizations. Educational Administration Quarterly, 18(3), 65-88. 
Mumford, E. (1972). Job Satisfaction: A Study of Computer Specialists. New York: Longman.

Ng, S. K. (1998). A profile of job satisfaction among physical education teachers in Hong Kong and their intention to change jobs. Journal of Physical Education and Recreation (Hong Kong), 4(1), 29 - 41.

Ng, S. K. (2002). A discussion on the role conflict between Hong Kong physical education teachers and coaches. Journal of Physical Education and Recreation (Hong Kong), $8(1), 59-63$.

Norusis, M. (1990). SPSS Advanced Statistics User's Guide. Chicago: SPSS.

Parasuraman, S. (1982). Predicting turnover intentions and turnover behavior: A multivariate analysis. Journal of Vocational Behavior, 21(1), 111-121.

Pastor, M. C., \& Erlandson, D. A. (1982). A study of higher order need strength and job satisfaction in secondary public school teachers. Journal of Educational Administration, 20(2), Summer, 172-183.

Pelsma, D. M., Richard, G. V., Harrington, R. G., \& Burry, J. M. (1989). The quality of teacher work life survey: A measure of teacher stress and job satisfaction. Measurement and Evaluation in Counseling and Development, 21(4), January, 165-176.

Perkins, C. M. (1991). A Study to Investigate Experienced Teachers' Job Satisfaction and the Teachers' Perception of Their Principals' Leadership Style (Doctoral Dissertation. The University of North Carolina at Chapel Hill). Dissertation Abstracts International, 52, A4171.

Poppleton, P. (1988). Teacher professional satisfaction: Its implications for secondary education and teacher education. Cambridge Journal of Education, 18(1), 5-16.

Portigal, A. H. (1976). The OECD Social Indicator Development Programme Special Studies No.1: Towards the Measurement of Work Satisfaction. United Kingdom: OECD.

Proctor, J., Rowlands, V., \& Thornton, R. (1989) Professional mugging, NATFHE Journal, Summer, 1989.
Quarstein, V. A., McAfee, R. B., \& Glassman, M. (1992). The situational occurrences theory of job satisfaction. Human Relations, 45(8), 859-872.

Reese, S. G., \& Johnson, D. J. (1991). Teacher job satisfaction and teacher job stress: School size, age and teaching experience. Education, 112, Winter, 247-253.

Segrave, J. O. (1981). Role preferences among prospective physical education teacher/coaches. NAPEHE Annual Conference Proceedings, II, 70-81.

Sergiovanni, T. J. (1967). Factors which affect satisfaction and dissatisfaction of teachers. The Journal of Education Administration, 5(1), 66-82.

Smith, P. C., Kendall, L. M., \& Hulin, C. L. (1969). The Measurement of Satisfaction in Work and Retirement. Chicago: Rand McNally.

Stroot, S., Collier, C., O'Sullivan, M., \& England, K. (1994). Contextual hoops and hurdles: Workplace conditions in secondary physical education. Journal of Teaching in Physical Education, 13, 342-360.

Subsidized Secondary Schools Council (1990). A Study on Teacher Wastage. Hong Kong: Author.

Templin. T. J., Sparkes, A., Grant, B., \& Schempp, P. (1994). Matching the self: The paradoxical case and life history of a late career teacher/coach. Journal of Teaching in Physical Education, 13, 274-294.

Tse, O. N. (1982). Occupational Stress and Job Satisfaction Among Hong Kong Secondary School Teachers: Directions for Administrators. Unpublished master's thesis, University of Hong Kong, Hong Kong.

Vroom, V. H. (1964). Work and Motivation. New York: Wiley and Sons, Inc.

\section{Correspondence:}

Author: Ng Siu Kuen, Robert, $\mathrm{PhD}$ 吳兆權

Affiliation: Physical Education Section, The Hong Kong Polytechnic University, HONG KONG

Address: 11 Yuk Choi Road, Hung Hom, Kowloon, Hong Kong 香港理工大學學生事務處體育組

E-mail: sarobert@polyu.edu.hk 